\title{
A FORMAÇÃO DO PROFESSOR DE LÍNGUAS EM UMA PERSPECTIVA DE EDUCAÇÃO INTERCULTURAL CIDADÃ
}

\section{LANGUAGE TEACHER EDUCATION IN THE PERSPECTIVE OF CRITICAL CITIZENSHIP EDUCATION}

\section{Joel Windle*}

\section{RESUMO}

Embora a formação de cidadãos esteja no centro das políticas públicas para o ensino básico, nem sempre o futuro professor de línguas estrangeiras é preparado para alcançar tal objetivo. O projeto analisado aqui buscou a desenvolver a capacidade dos licenciados de incluir dimensões de cidadania intercultural na sua prática docente. $\mathrm{O}$ trabalho envolveu reflexões sobre narrativas e diálogos interculturais, e propostas para a sua incorporação na sala de aula. $\mathrm{O}$ artigo contribui para repensar a relação entre direitos humanos e noções de cidadania, chamando atenção para a importância, na sua definição, de mobilizações coletivas e da construção de comunidades por meio de comunicações focadas em finalidades sociais e políticas.

Palavras-chave: cidadania intercultural ${ }_{i}$ multilinguismo; direitos humanos ${ }_{i}$ formação docente.

\section{ABSTRACT}

Although education for citizenship is central to public education policies, trainee foreign language teachers are not always prepared to achieve this goal. The project analyzed here sought to develop the ability of undergraduate students to include dimensions of intercultural citizenship in their teaching practice. The project involved reflections on narratives and intercultural dialogues, and proposals for their incorporation into the classroom. The article contributes to a rethinking of the relationship between human rights and notions of citizenship, calling attention to the importance of collective mobilizations and the construction of communities through communications focused on social and political ends. Keywords: human rights; teacher education; citizenship; intercultural education.

As políticas públicas brasileiras estabelecem o ensino básico como o lugar privilegiado da formação do cidadão, destacando o caráter cada vez mais globalizado da sociedade contemporânea. Embora a relação entre língua e cultura esteja no centro de debates sobre a formação do professor de línguas estrangeiras

\footnotetext{
* Univerisidade Federal Fluminense, Niterói (RJ), Brasil. e Faculty of Education at Monash, Austrália. jawindle@gmail.com
} 
há bastante tempo, são poucas as propostas teóricas e pedagógicas para enquadrar os conteúdos culturais e linguísticos dentro de uma perspectiva cidadã. Nesse contexto, a perspectiva dos direitos humanos aparece como uma justificativa e como um meio concreto para casar objetivos da pedagogia crítica com práticas ao nível da sala de aula (GUILHERME, 2002). A educação em direitos humanos (buman rights education), associada com a educação pela paz (Peace education) e educação pela cidadania democrática, se coloca como uma possibilidade curricular que encontra respaldo institucional em documentos legais nacionais e internacionais, principalmente os da ONU, assim como um vocabulário em uso cotidiano como parte das lutas sociais. No âmbito nacional, o Ministério da Educação reúne várias ações e documentos relacionadas a diversidade sob a etiqueta de direitos humanos, inclusive por meio de um Plano Nacional de Educação em Direitos Humanos publicado em 2007 (MEC, 2007).

Se a educação em direitos humanos aparece como um meio concreto de encaixar perspectivas críticas, essa abordagem sofre, ao mesmo, tempo das limitações de um certo universalismo, individualismo e legalismo (CRUFT, 2005). Como discurso universalista, os direitos humanos estão em tensão com o relativismo cultural presente na linguística aplicada crítica (PENNYCOOK, 2001; IYER et al., 2014). Com um foco no indivíduo e em proteções/ações individuais garantidas por mecanismos judiciais, os direitos humanos também deixam do lado certas questões de organização coletiva e de ações comunitárias subalternas (tais comunidades são reduzidas a "categorias"). Os documentos oficiais têm foco na apresentação e definição de direitos, assim como uma internalização da necessidade de respeita-las, com um pano de fundo da

reorganização da sociedade civil transnacional, a partir da qual redes de ativistas lançam ações coletivas de defesa dos direitos humanos (campanhas, informações, alianças, pressões etc.), visando acionar Estados, organizações internacionais, corporações econômicas globais e diferentes grupos responsáveis pelas violações de direitos. (MEC, 2007)

O paradigma emergente da educação intercultural cidadã (EIC) ${ }^{1}$ (BYRAM, 2008) oferece uma perspective que tem como foco justamente as questões coletivas e transnacionais. Os princípios da educação intercultural cidadão (BYRAM, 2008) são os seguintes: (a) a experiência intercultural ocorre quando pessoas de diferentes grupos sociais com valores, crenças e comportamentos diferentes se encontram, (b) ser «intercultural» envolve análise e reflexão sobre a experiência intercultural e a tomada de atitudes em função dessa reflexão; (c) a experiência de cidadania

1. No original, Intercultural Citizenship Education. 
intercultural ocorre quando pessoas de diferentes grupos sociais e culturas se envolvem em atividades sociais e políticas; $(\mathrm{d})$ a educação intercultural da cidadania envolve a mediação da experiência de cidadania intercultural; análise e reflexão sobre ela; e mudanças cognitivas, atitudinais, comportamentais, de autopercepção e de relacionamento com os outros. Esses princípios se juntam a dimensões pedagógicos da educação intercultural, principalmente o desenvolvimento de uma orientação comparativa (justaposição) nas atividades de ensino e aprendizagem; a criação de uma comunidade de ação e comunicação; e uma ênfase em uma conscientização da construção de identidades dentro de contextos sociais onde existem relações de poder desiguais (BYRAM, 2008; GORSKI, 2008).

A ideia da construção e mobilização de comunidades transnacionais - objetivo da educação intercultural cidadã - está em sintonia com noções comunicativas da aprendizagem de língua para participação em determinadas comunidades (de fala, de discurso, etc.) (HYMES, 1972; ALPTEKIN, 2002). Certamente, a noção de comunidade é diferente quando se fala em EIC e em competência comunicativa, mas no mínimo podemos pensar com uma unidade multidimensional única para definição de ação pedagógica de ensino de línguas.

A EIC toma como ponto de partida pedagógica a figura do cidadão intercultural - definido como alguém que adquire competências para participar de comunidades transnacionais, sempre mantendo sua identidade de cidadão de um estado específico. Assim, a abordagem intercultural foge do modelo de adequação dos alunos ao padrão cultural e linguístico do 'falante nativo', no caso de inglês, geralmente um habitante de classe média e monolíngue de uma grande cidade americana ou inglesa (RAJAGOPALAN, 2005; RAJAGOPALAN, 2012). Esse modelo dominante inclui uma dimensão racial implícita, quase sempre apresentando, em situações de ensino, falantes da língua alvo brancos, e desvalorizando outras culturas, inclusive a brasileira (MOITA LOPES, 1996; JORDÃO, MARTINEZ e HALU, 2014). A educação em direitos humanos, como paradigma, nem sempre consegue alcançar questões político-linguísticas por não ter uma teoria da comunicação entre coletividades, nem da construção de coletividades e de valores/ reivindicações pela comunicação.

Um foco na educação intercultural permite reconhecer o crescente hibridismo linguístico e cultural no contexto da globalização, que já constitui um objeto de estudos maduro dentro da linguística aplicada (CANAGARAJAH, 2007; JØRGENSEN, 2008; OTSUJI e PENNYCOOK, 2010; BLOMMAERT e RAMPTON, 2011). Os resultados acumulados destas pesquisas apontam para a importância de tratar questões de identidade e de poder social na análise de escolhas 
e estratégias linguísticas (RAJAGOPALAN, 2011; RUBDY e ALSAGOFF, 2013; BORDINI e GIMENEZ, 2014).

A apropriação do inglês em práticas culturais dentro de comunidades transnacionais vem constituindo um vetor de solidariedade entre grupos marginalizados (PENNYCOOK, 2007; WINDLE, 2015). Internacionalmente, a ideia de competência intercultural, baseado em normas de interação dentro de comunidades transnacionais, tem sido incorporado em modelos de competência comunicativa intercultural (ALPTEKIN, 2002), construindo, ao mesmo tempo, um "terceiro espaço" para aprendizagem (GUTIÉRREZ, BAQUEDANO-LÓPEZ e TEJEDA, 1999; BIGELOW, 2011). Esse movimento vai ao encontro de pesquisas brasileiras mostrando a importância de espaços virtuais, especialmente com as possibilidades produtivas da Web 2.0 na construção e defesa de identidades oprimidas de raça, gênero, sexualidade e classe social (MOITA LOPES, 2010; MELO e MOITA LOPES, 2013).

Os direitos humanos poderiam, em relação à EIC, ser considerados como discurso e como estratégia política construído em determinadas comunidades, em vez de um quadro fixo de valores fora das relações sociais ou sempre capaz de analisa-las. Essa distinção, porém, não está muito em evidência na literatura, que tende a usar como sinônimo os termos de direitos humanos, cidadania democrática, e cidadania intercultural (KERR e KEATING, 2011). O presente artigo relata um projeto baseado no conceito de EIC, mas que revelou a centralidade do discurso de direitos humanos - tanto nas reflexões dos participantes quanto na sua visão de prática na sala de aula de línguas. Assim EIC não vem para substituir direitos humanos, mas como um quadro que tem o potencial de colocar em diálogo perspectivas críticas sobre direitos humanos e perspectivas linguísticas críticas.

O restante desse artigo analisa um projeto de formação de professores de língua inglesa, destacando como ele tentou concretizar princípios da EIC e de qual forma aparece o discurso de direitos humanos dentro dessa proposta. A narrativa construída é do pesquisador investigando sua própria prática, o que implica algumas lacunas e uma possível tendência a auto-promoção. O objetivo, porém, não é de avaliar o sucesso do projeto em si, mas de buscar os pontos de contato entre EIC e direitos humanos, pensando na especificidade de comunidades e ações transnacionais como foco. Além do relato da proposta e das atividades, o artigo analisa alguns exemplos de reflexões dos participantes e os resultados de um questionário sobre EIC aplicado antes e depois do projeto, seguindo modelos existentes (MATVEEV e MERZ, 2014). 


\section{CONTEXTO}

O projeto objeto desse artigo, com o nome Diálogos Críticos, fez parte da disciplina Linguística Aplicada na licenciatura em língua inglesa da Universidade Federal Fluminense. A intervenção se articulou com um projeto de pesquisa que tem como objetivo contribuir para a reformulação da grade curricular das licenciaturas (intitulado 'Narrativas de diversidade e diálogo intercultural: desenvolvimento de um modelo de aprendizagem colaborativa internacional'). O projeto contribui, também, para uma ação de extensão em colaboração com a Fundação Municipal de Educação de Niterói (FME), que envolve a produção de material didático por alunos da licenciatura em língua inglesa a ser usada na rede municipal (intitulado 'Desenvolvimento do ensino de culturas e linguas na educação básica de Niterói'). Três professores da rede municipal, atuando na coordenação de línguas na FME, participaram do projeto Diálogos Críticos na fase de avaliação dos trabalhos da turma de licenciandos. Outros dois professores do setor de língua inglesa da UFF trabalharam em paralelo o tema da mulher na sociedade no mesmo semestre, compondo, assim, um movimento para reforma da grade curricular do curso em torno de grandes eixos temáticos ligados, nos termos do processo de reforma, aos direitos humanos.

Diálogos Críticos contou, ainda, com a participação de parceiros internacionais por meio de entrevistas por Skype com professores originários do Iraque, da África do Sul, dos Estados Unidos e da Austrália. Alguns dos entrevistados, além de apresentar experiencias culturais, sociais e linguísticas próprias a contextos nacionais distintos, são integrantes históricos de movimentos sociais construídos por meio de comunidades transnacionais.

\section{DEFINIÇÕES DE OBJETOS/OBJETIVOS TEÓRICOS E INSTITUCIONAIS}

O projeto Diálogos Críticos visou contribuir à formação professores que sejam capazes de pensar na construção do conhecimento de forma colaborativa, inclusive no desenvolvimento de habilidades linguísticas, a partir do diálogo intercultural. Parte desse objetivo envolve romper com a visão da língua inglesa como estrangeira, única, propriedade de falantes "nativos" e que ocupa apenas espaços escolares e sociais elitizado (JORDÃO, 2011). Diálogos Críticos pretendeu mostrar a riqueza da aprendizagem, apropriação e uso de recursos linguísticos de diversas origens nos contextos de lutas sociais e afirmação de identidades marginalizadas. Esse trabalho se baseou, inicialmente, em atividades elaboradas a partir do documentário 
Human, que aborda questões comuns à condição humana - o título já invocando o universalismo dos direitos humanos.

Além de contemplar a linguística aplicada, foram priorizados conteúdos transversais - articulados institucionalmente em termos de direitos humanos - que fazem parte de uma reforma da grade curricular da Universidade Federal Fluminense: diversidade étnico-racial, diversidade de gênero e diversidade religiosa. Mais especificamente, o projeto contribuiu para preparar futuros professores a ensinar noções da Lei Maria da Penha em todas as disciplinas, estabelecida como prioridade curricular nas escolas estaduais do Rio de Janeiros pela Lei $\mathrm{n}^{0} 7.477$, de novembro de 2016, e concretizado pela programa 'Lei Maria da Penha vai à Escola'. Essa Lei define como propósito, no Art. 3, III:

Conscientizar adolescentes, jovens e adultos, estudantes e professores, que compõem a comunidade escolar, da importância do respeito aos Direitos Humanos, notadamente os que refletem a promoção da igualdade de gênero, prevenindo e evitando, dessa forma, as práticas de violência contra a mulher. (GOVERNO DO ESTADO DO RIO DE JANEIRO, 2016)

O intercultural foi apresentado como um caminho para a construção da identidade e da linguagem, fora de um quadro de unidades culturais distintas, rígidas e homogêneas, baseadas em estados-nação (MACDONALD, 2003; PENNYCOOK, 2007). A síntese de linhas críticas de estudos de letramentos de Lewison e outros (LEWINSON; FLINT; VAN SLUYS, 2002) identifica várias conexões relevantes a uma pedagogia do diálogo intercultural que fez parte do trabalho: 1. interromper o senso comum, 2. interrogar múltiplos pontos de vista, 3. focar em questões sócio-políticas, 4. tomar atitudes e promover a justiça social. O uso de narrativas pessoais permitiu a contemplação do processo de construção histórica do conhecimento (SHOR, 1987) e a inclusão de perspectivas divergentes (LUKE; IYER: DOHERTY, 2010). Essa abordagem também oferece espaço para o trabalho com mídias e cultura popular (VASQUEZ, 2000), e para a consideração das dinâmicas de poder na sociedade (BOOZER et al., 1999).

Assim, a concepção do projeto envolve um quadro teórico onde a noção de comunidade aparece em diversos momentos, assim como um questionamento de fronteiras culturais, sociais e linguísticos entre comunidades. Ao mesmo tempo, o quadro institucional é de um movimento de inclusão de direitos humanos ao nível do currículo da universidade pública, e no ensino básico ao nível do estado. Os próprios alunos mostraram uma preferência marcada pelo tratamento de questões de diversidade por meio de discussão de direitos humanos (Tabela 1). Enquanto $80 \%$ avaliou como muito importante discussão de direitos humanos para tratar da 
diversidade, discussão de notícias (abordagem principal dos livros didáticos), é avaliado como muito importante por apenas $30 \%$.

Tabela 1. 'Qual a importância de cada uma dessas áreas de discussão quando o objetivo é desenvolver o respeito pela diversidade na sala de aula de inglês?' ( $\mathrm{N}=56)$

\begin{tabular}{|l|c|}
\hline Abordagem à diversidade & \% 'muito importante' \\
\hline Direitos humanos & 80 \\
\hline Experiências pessoais & 59 \\
\hline $\begin{array}{l}\text { Tópicos comparativos como variações culturais na culinária, nos compor- } \\
\text { tamentos ou nos sotaques }\end{array}$ & 38 \\
\hline Diferenças de opinião dentro do círculo familiar & 34 \\
\hline Notícias e assuntos atuais & 30 \\
\hline
\end{tabular}

Uma das atrações dos direitos humanos como plataforma é justamente a impessoalidade, pois metade dos alunos avaliaram que "deve-se conhecer muito bem uma pessoa antes de abordar temas sensíveis" - o que seria um argumento contra o uso de exemplos do círculo familiar, por exemplo. A quase totalidade dos alunos consideram que "professores devem estabelecer um ambiente de respeito mútuo antes de qualquer debate em sala de aula". Essa preocupação está evidente em relação às formas linguísticas encontradas para negociar pontos de vista diferentes, e novamente a atração de direitos humanos como um ponto de referência aparentemente neutro.

\section{IMPLEMENTAÇÃO DO PROJETO}

O projeto se iniciou com a apresentação de narrativas do documentário Human do diretor francês Yann Arthus-Bertrand (2015), fruto de cinco anos de entrevistas com mais de 2.000 pessoas ao redor do mundo. Os entrevistados relatam suas experiencias, crenças e valores cerca de temas como o amor, o trabalho, a pobreza, a educação, Deus, e a mulher. As entrevistas acontecem em várias línguas, e todas estão disponíveis com legendas em inglês e português no Youtube.

Vários estudiosos da linguística aplicada valorizam a narrativa em primeira pessoa como ferramenta de ensino e pesquisa (PENNYCOOK, 2004, KRAMSCH, 2008), uma vez que as "narrativas evocativas" reconstroem ricas descrições de eventos particulares que levam a uma série de reflexões sobre questões específicas, como relações de raça, gênero e classe social (ELLIS et al., 2000, p. 744). A utilização 
pedagógica dessas narrativas abre ricas possibilidades para reflexão e permite que uma parte importante da prática acadêmica se torne visível para além da sala de aula.

Criamos o grupo na rede social Facebook Critical Dialogues para estabelecer uma comunidade transnacional envolvendo discussão dos depoimentos e propostas didáticas. Para refletirmos sobre o uso de narrativas interculturais no ensino de língua estrangeira, postamos na comunidade online alguns depoimentos do filme Human sobre o tema da mulher, e respostas às seguintes perguntas em relação ao uso didático de cada narrativa para uma turma de ensino básico em um contexto especificado por cada aluno: 1) por que eu deveria ensinar essa aula? 2) quais atividades serão incluídas na aula? 3) a lição vai ser muito fácil / difícil para esta turma? 4) qual o papel que assumirei durante esta aula? Os licenciados, além de colocar suas ideias, avaliaram as propostas dos colegas, propondo sugestões para modificar as aulas propostas. Apesar da preferência expressa para formas de discussão impessoais, a maioria de propostas didáticas para o ensino básico focou em relações dentro do lar, tentando promover empatia e compreensão da posição dos outros. Por exemplo:

As a warm up I would make questions to them related to gender roles, asking them if they do some work at home (for example: who does the chores?). After that I would make them work in pairs and do a role play game when the boys will be the women for a moment and the girls will be the men. Then, they will act as they were their parents and reflects about the roles each of them have in the house. This activity aims to make the boys aware of the hard work women have at home to keep up with the house even after they've spent most part of their days working outside.

Pensando nas formas de discutir as narrativas também, e usando frases tiradas das narrativas de Human, transformamos as colocações em diálogos onde diferentes opiniões são comparadas e conflitos de valores são abordados. Por isso, trabalhamos expressões de concordância e discordância, de conceição e de divergência. Esse trabalho foi importante para ajudar os alunos a se expressar e a falar sobre assuntos sobre os quais não há unanimidade, trabalhando estratégias de diálogo. Essas funções linguísticas são ausentes, ou minimizadas, nos principais métodos de ensino de língua estrangeira que têm foco na precisão e fluência em situações harmoniosas de comunicação monocultural e monolingual. As expressões trabalhadas foram aproveitadas em debates em sala de aula, em contribuições ao fórum, e nas propostas didáticas para o ensino básico no trabalho final.

O próximo passo foi a produção e gravação de entrevistas sobre o tema da mulher na sociedade que possam trazer perspectivas interculturais e responder às dúvidas da turma sobre os papéis, tratamentos, direitos e experiências de gênero em diferentes contextos. A turma elaborou uma lista de tipos de pessoa que gostariam 
de entrevistar, e um rótulo de perguntas, aproveitando a comunidade online para juntar e selecionar as perguntas a serem feitas. Os alunos fizeram as entrevistas usando Skype e postando as gravações na comunidade online da turma (Tabela 2).

\section{Tabela 2. Entrevistados do projeto Diálogos Críticos}

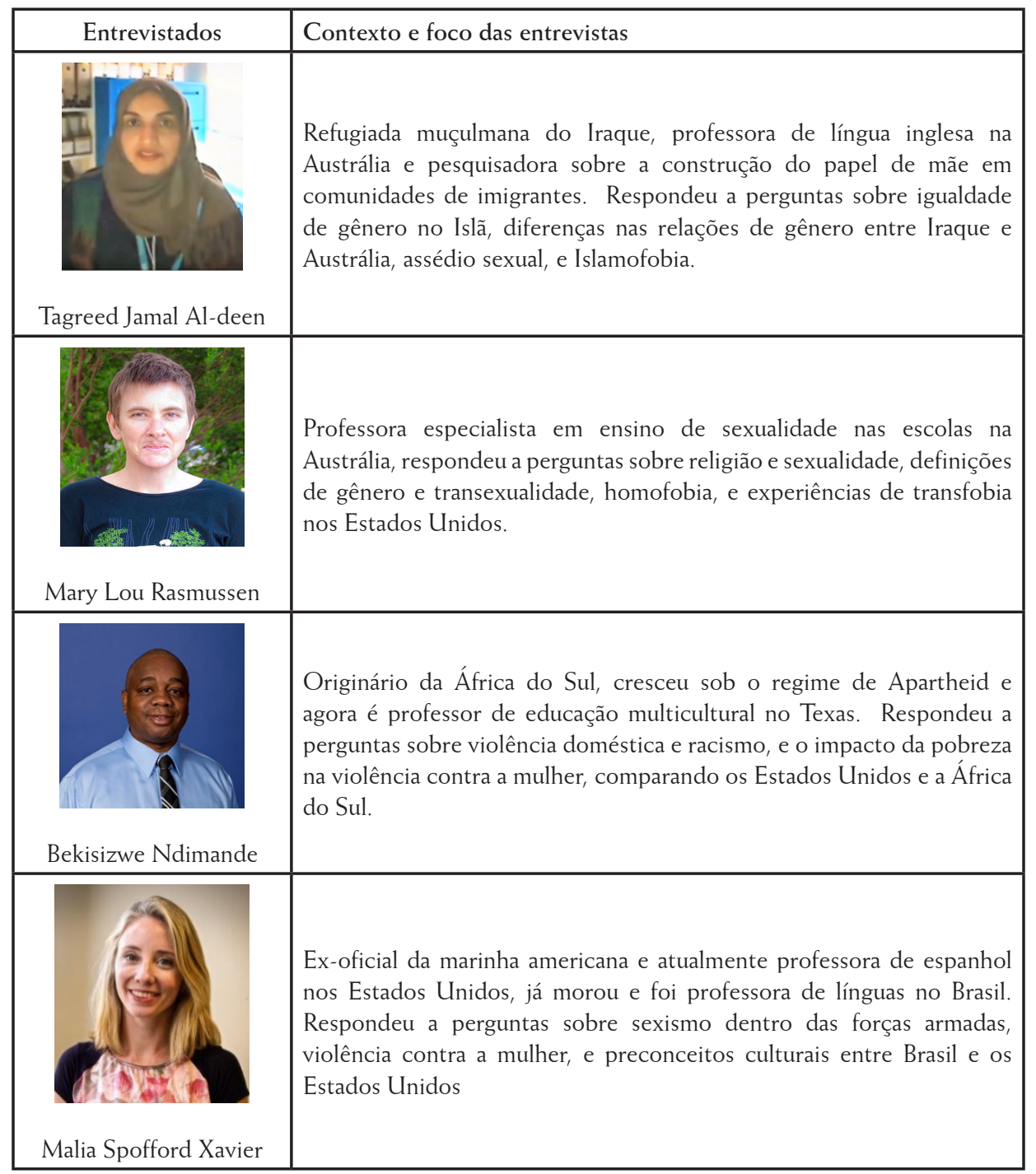

Essas entrevistas constituíram a base de reflexões em forma de um diário, e também alimentaram propostas didáticas para uma aula no ensino básico juntando 
objetivos interculturais e linguísticos. Muitas perguntas foram de cunha pessoal, mas outras levantaram dimensões comparativas, inclusive voltado para condições econômicas, como mostra o seguinte exemplo:

Extrato de entrevista com Bekisizwe Ndimande, resposta à pergunta "In Brazil, black women are the ones who suffer more with domestic violence and misogyny. Do you think it is the same in South Africa?"

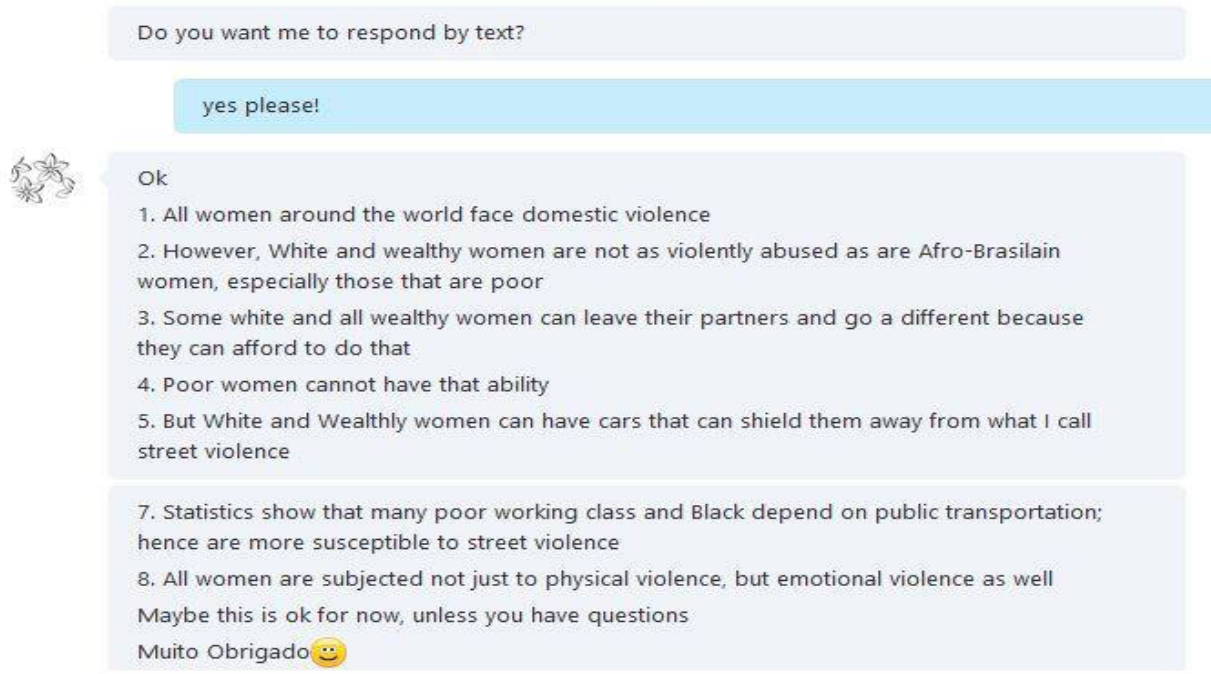

Referência explícita a direitos humanos está quase ausente dessa parte do projeto, mas discussão de movimentos sociais e políticos estava muito presente, assim como reflexões pessoais, usando termos tais "igualdade", "discriminação" e "opressão".

O trabalho final foi um projeto colaborativo e interativo sobre o tema da mulher na sociedade, com a opção de fazer ligações com a Lei Maria da Penha prioridade curricular para o ensino básico do Estado do Rio de Janeiro (2016). Como parte desse trabalho, os alunos produziram um pôster apresentando sua proposta com os seguintes elementos: contexto (tipo de escola, localização, nível, número de alunos); objetivos de aprendizagem (o que espera que os alunos aprendam, incluindo a compreensão intercultural e objetivos linguísticos; justificativa (por que o tópico é relevante, por que deve ser ensinado aos alunos); metodologia (descrição dos recursos a serem utilizados, breve resumo das atividades, descrição breve de quais as aulas antes deste e o que seguirá na próximas aulas; referências. 
Os pôsteres (Tabela 3) foram apresentados aos pares e a uma banca de professores da rede municipal de ensino fundamental da cidade de Niterói atuando na coordenação de línguas estrangeiras. Os colegas e a banca deram retorno por meio de anotações ao lado de cada pôster, sendo que os autores dos pôsteres também responderam aos comentários no mesmo espaço, construindo um diálogo e contribuindo para o desenvolvimento do trabalho completo, entregue posteriormente.

\section{Tabela 3. Títulos dos pôsteres com tradução para português}

Gender equality: the lack of women in prestigious positions

Igualdade de gênero: a falta de mulheres em posições de prestígio

Muslim women: prejudice \& information, an equation to be resolved

Mulheres muçulmanas: preconceito e informação, uma equação a ser resolvida

Discussing domestic violence inside the school context: bow women face domestic violence?

Discutindo a violência doméstica dentro do contexto escolar: como as mulheres enfrentam violência doméstica?

Deconstructing sexism: the role of women in Society

Desconstruindo o sexismo: o papel das mulheres na sociedade

Abusive relationships: different types of violence against women

Relações abusivas: diferentes tipos de violência contra as mulheres

Sbould I stay or sbould I go? Domestic violence witbin language

Devo ficar ou devo ir? Violência doméstica dentro da linguagem

Rupi kaur and the importance of art

Rupi kaur e a importância da arte

Discussing gender roles

Discutindo papéis de gênero

Women are not objects: bow women are treated in Society

As mulheres não são objetos: como as mulheres são tratadas na sociedade

Gender roles and stereotypes

Papéis e estereótipos de gênero

Approaching the theme of violence against women

Abordando o tema da violência contra as mulheres 
Then princess. Now, generals: how women are portrayed in society

Antes, princesas. Agora, generais: como as mulheres são retratadas na sociedade

Violence against women: the importance of bringing real issues to the classroom

Violência contra as mulheres: a importância de trazer problemas reais para a sala de aula

$\mathrm{Na}$ apresentação desse trabalho, os direitos humanos apareceram, em raros momentos, como um termo unificador para questões mais especificas - ligadas a formas de opressão e mobilizações/formas de resistência distintas, como mostra o seguinte exemplo:

It is very important that we lead our students to think about diverse cultures and themes, to discuss relevant human rights problems, such as religious intolerance, misogyny, and racism. Moreover, we should break stereotypes and promote an intercultural teaching that is more faithful to reality... By proposing an education that considers the strengthening of respect for human rights, fundamental freedom, minorities, and tolerance, it is also necessary to consider that there will be difficulties in its implementation.

Muitas propostas envolveram investigação de movimentos sociais, apreciação de ambientes políticos diferentes, como mostra o seguinte exemplo do trabalho final:

The first activity is based on a campaign that started spontaneously in Australia. As Taghreed mentioned, after a terrorist attack people see Muslim people with bad eyes, especially Muslim women, because of the hijab. So, after a post in Twitter, many Australians started tweeting messages to support Muslims fearing backlash and the campaign reached great proportions. We planned this activity to provoke a more critical thinking on students.

A proposta termina com os próprios alunos produzindo hashtags de campanha para assuntos que eles mesmos identificam como importantes.

\section{OS CAMINHOS DA APRENDIZAGEM}

A avaliação interativa, com participação de uma banca de especialistas na amostra de pôsteres sobre ensino intercultural, ajudou muito a aproximar os alunos às realidades do ensino básico. Essa avaliação validou o trabalho dos alunos, trazendo também novas ideais para aperfeiçoar as suas propostas antes de entregálas na forma final (de um artigo de 10 páginas).

O questionário aplicado no início do semestre mostrou que os alunos tinham abertura para trabalhar com ideias interculturais, que eles valorizaram como parte do papel do professor de línguas. Uma maioria afirmou tentar se colocar no lugar 
do outro quando se depara com uma opinião diferente da sua, mais um terço afirma não se sentir à vontade para conversar sobre temas polêmicos na sala de aula.

$\mathrm{O}$ questionário do final do curso mostrou que foram as reflexões sobre o documentário Human, as entrevistas por Skype e o retorno da banca de especialistas do ensino básico que mais ajudaram a refletir sobre as questões de diversidade cultural (90\% afirmou que ajudaram muito). As discussões com os colegas e o professor também foram proveitosas, mas as ferramentas mais tradicionais - leituras teóricas e o diário - foram menos úteis para a aprendizagem (ajudou no máximo 'um pouco' para refletir sobre a diversidade na visão de uma maioria da turma). Esses resultados mostram o interesse na criação de uma comunidade transnacional para promover a cidadania intercultural.

Mais da metade considerou que a disciplina mudou sua perspectiva sobre as relações entre cultura e língua no ensino e 80 porcento avaliou que o projeto colocou alguns dos seus pressupostos em questão. Uma maioria concordou plenamente que o projeto "abriu novos caminhos para pensar sobre métodos de ensino de língua estrangeira" (66\%), que o "sensibilizou a diferentes formas de preconceito e injustiça (86\%) e que o "ajudou a refletir sobre meus próprios valores" (93\%).

Do ponto de vista do professor-pesquisador, o projeto Diálogos Críticos mostrou a importância do contato direto com o 'outro' para a criação de laços de solidariedade transnacional, visível nos diários dos alunos relatando o impacto das entrevistas feitas por Skype. Ao mesmo tempo, esse trabalho exigiu que eu, como professor, abrisse mão de certo controle sobre a direção da disciplina para deixar os alunos seguir as suas preocupações. Isso ficou evidente na hora de escolher perguntas para usar nas entrevistas. Várias perguntas eu considerei indelicadas ou impossíveis de serem respondidas (por exemplo, 'você gosta de ser mulher'). Porém, essas perguntas foram as mais proveitosas, e não incomodaram nem um pouco os entrevistados. O caminho mais imprevisível do projeto, em relação a uma disciplina tradicional, incomodou alguns alunos. Por exemplo, uma aluna relatou o desconforto tanto com a discussão de temas sensíveis quanto com as incertezas nas exigências. $\mathrm{O}$ projeto, por tocar em assuntos pessoais e diferenças culturais, também exigiu do professor reflexões sobre suas próprias experiências e perspectivas, e o compartilhamento dessas com a turma. Uma das demandas da turma, inclusive, foi uma entrevista com o professor, o que não aconteceu por falta de tempo.

A participação dos colaboradores do ensino básico da cidade e de fora do Brasil foi realmente um elemento muito interessante. É importante notar que o modelo apresentado de competência linguística não foi do falante nativo de inglês, mas de pessoas multilíngues falantes de inglês como língua adicional. Isso só foi 
possível graças à integração do projeto Diálogos Críticos com outras ações de extensão e de pesquisa.

\section{CONCLUSÃO}

O projeto apresentado nesse artigo abre espaço para uma apreciação melhor da relação entre ensino em direitos humanos e outras concepções guiando ensino de línguas - principalmente a educação intercultural cidadã. $O$ projeto ganhou vida institucional em função de novas exigências para o tratamento da diversidade na sala de aula da universidade e da escola em termos de direitos humanos. Os licenciandos (na verdade 80\% licenciandas), mostraram uma forte preferência para discussão de diversidade apoiado polo discurso de direitos humanos, em vez de outras abordagens pessoais ou textuais. Essa preferência não se manifestou de forma explícita na maior parte das discussões e produções, porém algumas reflexões deixaram claro que as diversidades em questão são, de forma implícita, ligadas ao termo unificador de direitos humanos.

Por outro lado, a presença e a construção de comunidades de ação transnacionais, central a EIC, se fez evidente ao longo do projeto. Alguns alunos, que já usaram inglês para participar de movimentos sociais online, apresentaram propostas voltadas para desenvolvimento e participação em ações coletivas contra diversas formas de opressão e discriminação, se apropriando da linguagem de movimentos sociais. O próprio projeto iniciou, de forma modesta, alguma comunidade transnacional temporária. Enfim, os entrevistados relataram experiencias dentro de movimentos sociais (LGBT, feminista, anti-Apartheid) que tinham uma dimensão transnacional.

Os dois conceitos (Educação em Direitos Humanos e Educação Intercultural Cidadã) têm, assim, importância na construção de posicionamentos críticos e engajados na sala de aula. Os alunos já trazem uma certa bagagem e afinidade com o conceito de direitos humanos, que já carrega associações com movimento, defesa e campanha. A noção de cidadania intercultural acrescenta uma teoria da ação, e uma inserção das definições (declaração de direitos) numa visão mais dinâmica de lutas e movimentos no qual o coletivo é essencial. Os direitos humanos, como objeto de estudo na sala de aula, não implicam nas estratégias de luta e ação que a noção de cidadania intercultural traz.

Para o ensino de línguas estrangeiras, a dimensão intercultural é essencial para situar a ação cidadã em relação à construção de comunidades de ação pela comunicação em diversos códigos e discursos, além do espaço nacional. Oferece, 
assim, uma abertura para romper com as fronteiras que separam o aluno e o professor de inglês de uma apropriação da língua para finalidades sociais e políticas 'autênticas'. A reflexão sobre as interações e diferenças entre distintos grupos pode, também, relativizar o discurso de direitos humanos como construído em determinados contextos, como incompleto, e como parte apenas das possibilidades de estratégias de luta para justiça social (outro termo que tem ressonância e capacidade de mobilização variável entre e dentro de comunidades). Assim, as práticas interculturais ajudam a fugir do modelo direitos-humanos $>$ cidadão global, que na realidade impõe um modelo ocidental de cidadania no mundo como parte de uma dinâmica colonizadora (MIGNOLO, 2009; 2012).

Ainda falta trabalho teórico para definir melhor a relação entre diversas concepções da cidadania e os direitos humanos - tanto na visão dos licenciandos quanto dentro de propostas pedagógicas. São necessárias mais pesquisas empíricas também para verificar quais estratégias e discursos realmente ajudam a transformar o ensino de língua estrangeira e a formação do professor de línguas. $O$ projeto relatado aqui, além de ser um caso limitado, beneficiou de algumas condições que podem ser consideradas raras, pelo menos atualmente, que são do contato direto transnacional por meio de Skype.

\section{$\overline{\text { REFERÊNCIAS }}$}

ALPTEKIN, C. (2002). Towards intercultural communicative competence in ELT. ELT journal, v. 56, n. 1, p. 57-64.

BIGELOW, M. (2011). (Con) Texts for cultural and linguistic hybridity among Somali diaspora youth. The New Educator, v. 7, n. 1, p. 27-43.

BLOMMAERT, J.; RAMPTON, B. (2011). Language and superdiversity. Diversities, v. 13, n. 2, p. 1-21. Disponível em: < http://www.mmg.mpg.de/fileadmin/user_upload/ Subsites/Diversities/Journals_2011/2011_13-02_art1.pdf > .

BORDINI, M.; GIMENEZ, T. (2014). Estudos sobre inglês como língua franca no Brasil (2005-2012): uma metassíntese qualitativa. Signum: Estudos da Linguagem, v. 17, n. 1, p. $10-43$.

BYRAM, M. (2008). From foreign language education to education for intercultural citizenship: Essays and reflections. Multilingual Matters. 
CANAGARAJAH, S. (2007). Lingua franca English, multilingual communities, and language acquisition. The Modern Language Journal, v. 91, n. s1, p. 923-939.

CRUFT, R. (2005). Human rights, individualism and cultural diversity. Critical Review of International Social and Political Philosophy, v. 8, n. 3, p. 265-287.

GEE, J. (2014) Social linguistics and literacies: Ideology in discourses. Routledge.

GORSKI, P. C. (2008). Good intentions are not enough: A decolonizing intercultural education. Intercultural education, v. 19, n. 6, p. 515-525.

GOVERNO DO ESTADO DO RIO DE JANEIRO. (2016). Lei n 7477 de 31 de outubro de 2016. Rioi de Janeiro: ALERJ.

GUILHERME, M. (2002). Critical citizens for an intercultural world. Foreign language education as cultural politics. Clevedon: Multilingual Matters.

GUTIÉRREZ, K. D.; BAQUEDANO-LÓPEZ, P.; TEJEDA, C. (1999). Rethinking diversity: Hybridity and hybrid language practices in the third space. Mind, culture, and activity, v. 6, n. 4, p. 286-303.

HYMES, D. (1972). On communicative competence. Sociolinguistics, v. 2, p. 269-293.

IYER, R. et al. (2014). Critical applied linguistics. In: LEUNG, C. e STREET, B. (Ed.). The Routledge Companion to English Studies. New York: Routledge. p.317-332.

JORDÃO, C. M. (2011). A posição de professor de inglês no Brasil: hibridismo, identidade e agência. Letras \& Letras, v. 26, n. 2.

JORDÃO, C. M.; MARTINEZ, J. Z.; HALU, R. C. (2014). (Des)conforto nas práticas de professoras de Inglês. In: ZACCHI, V. J. e STELLA, P. R. (Ed.). Novos Letramentos: Formação de professores e ensino de língua inglesa. Maceio: Edufal. p.21-48.

JØRGENSEN, J. N. (2008). Polylingual languaging around and among children and adolescents. International Journal of Multilingualism, v. 5, n. 3, p. 161-176.

KERR, D.; KEATING, A. (2011). Intercultural, citizenship and human rights education: The challenges of implementation for policy, practice and research: Taylor \& Francis.

MATVEEV, A. V.; MERZ, M. Y. (2014). Intercultural Competence Assessment: What Are Its Key Dimensions Across Assessment Tools?. Toward Sustainable Development 
Through Nurturing Diversity: Selected Papers from the Twenty-First Congress of the International Associate for Cross-Cultural Psychology. p.141-153.

MEC. (2007). Plano Nacional de Educação em Direitos Humanos. Brasília: Secretaria Especial dos Direitos Humanos; Ministério da Educação.

MELO, G. C. V.; MOITA LOPES, L. P. (2013). As performances discursivo-identitárias de mulheres negras em uma comunidade para negros na Orkut. DELTA: Documentação e Estudos em Linguística Teórica e Aplicada, v. 29, n. 2, p. 237-265.

MEYER, J. W.; BROMLEY, P.; RAMIREZ, F. O. (2010) Human rights in social science textbooks: Cross-national analyses, 1970-2008. Sociology of Education, v. 83, n. 2, p. $111-134$.

MIGNOLO, W. (2009). The Idea of Latin America. Malden: John Wiley \& Sons.

MIGNOLO, W. (2012). Local histories/global designs: Coloniality, subaltern knowledges, and border thinking. Princeton: Princeton University Press.

MOITA LOPES, L. P. (2010). Os Novos Letramentos Digitais Como Lugares de Construção de Ativismo Político Sobre Sexualidade e Gênero. Trabalhos em Linguística Aplicada, v. 49, n. 2, p. 393-417.

MOITA LOPES, L. P. D. (1996). "Yes, nós temos bananas" ou "Paraíba não é Chicago, não": Um estudo sobre a alienação e o ensino de inglês como língua estrangeira no Brasil. In: MOITA LOPES, L. P. D. (Ed.). Oficina de lingüística aplicada. Rio de Janeiro: Mercado de Letras. p.37-62.

OTSUJI, E.; PENNYCOOK, A. (2010). Metrolingualism: Fixity, fluidity and language in flux. International Journal of Multilingualism, v. 7, n. 3, p. 240-254.

PENNYCOOK, A. (2001) Critical applied linguistics: A critical introduction. New York: Routledge, 2001.

PENNYCOOK, A. (2007). Language, localization, and the real: Hip-hop and the global spread of authenticity. Journal of Language, Identity, and Education, v. 6, n. 2, p. $101-115,2007$.

PENNYCOOK, A. (2010) Critical and alternative directions in applied linguistics. Australian Review of Applied Linguistics, v. 33, n. 2, p. 1-16. 
RAJAGOPALAN, K. (2005). A geopolítica da língua inglesa e seus reflexos no Brasil. São Paulo: Parábola Editorial. 135-159.

RAJAGOPALAN, K. (2011). O "World English"-um fenômeno muito mal compreendido. In: GIMENEZ, G.;CALVO, L. C. S., et al (Ed.). Inglês Como Lingua Franca: Ensino-Aprendizagem e Formaçao de Professores. Campinas: Pontes. p.45-57.

RAJAGOPALAN, K. (2012). For the umpteenth time, the "native speaker": or, why the term signifies less and less in the case of English as it spreads more and more throughout the world. In: LIMA, D. (Ed.). Language and its Cultural Substrate: perspectives for a globalized world. Vitória da Conquista: Uesb. p.37-58.

RAMIREZ, F. O.; SUÁREZ, D.; MEYER, J. (2007). W. The worldwide rise of human rights education. In: (Ed.). School knowledge in comparative and historical perspective: Springer. p.35-52.

RICHARDS, J. C.; LOCKHART, C. (1994). Reflective teaching in second language classrooms. Cambridge University Press.

RUBDY, R.; ALSAGOFF, L. (2013) The global-local interface and hybridity: Exploring language and identity. Bristol (UK): Multilingual Matters.

RUSSELL, S. G.; SUÁREZ, D. F. (2017). Symbol and substance: Human rights education as an emergent global institution. Human Rights Education: Theory, Research, Praxis, p. 19.

SUÁREZ, D. (2006). Education professionals and the construction of human rights education. Comparative Education Review, v. 51, n. 1, p. 48-70.

VAVRUS, F.; BARTLETT, L. (2006). Comparatively Knowing: Making a Case for the Vertical Case Study. Current Issues in Comparative Education, v. 8, n. 2, p. 95-103.

WINDLE, J. A. (2015) "white people are crazy. y'all hear me?": Interseccionalidade na construção de identidades coletivas online. IV Pensando Áfricas e Suas Diásporas. Mariana (MG): UFOP.

Recebido: $13 / 03 / 2018$

Aceito: 06/06/2018 